\title{
Text Selection and Course Design: Faculty Perspectives on Critical Reading and Critical Thinking
}

\author{
Julie Collins-Dogrul \\ Whittier College \\ jcollins@,whittier.edu
}

\author{
Kenia Saldaña \\ Whittier College
}

\begin{abstract}
This study of sociology faculty in twelve private colleges and universities compares teaching with textbooks and textbook alternatives in undergraduate classes. Faculty explain that textbooks provide a breadth of material that is organized and streamlined in a way that promotes consistency across instructors, facilitates content delivery to students with a range of abilities, and reduces course preparation time. Despite these benefits, faculty have a strong preference for textbook alternatives. Faculty argue that readings, like monographs and journal articles, develop students' critical reading and thinking skills. Additionally, when instructors design courses with alternative readings they engage their own critical reading and thinking, as they critique and synthesize the literature in their discipline in order to curate texts for the syllabus. We argue that teaching courses with alternative readings creates course experiences where students and faculty engage with a discipline together.

Keywords: textbooks, critical thinking, critical reading, sociology, course design
\end{abstract}

Texts are essential to course design. They shape how professors organize units, structure lectures, and assess learning. Despite the importance of choosing texts, systematic research concerned with why instructors choose textbooks or choose alternative readings is scarce. We surveyed thirty-six sociology professors at twelve small and medium private institutions to bring the pedagogy of choosing texts to the fore. This research asks, why do instructors choose textbooks, monographs, or other types of readings? How do instructors understand how the choice of one form of text or another shapes teaching and learning?

Our inductive qualitative analysis of open-ended survey interview questions, revealed that faculty view textbooks and their alternatives as fundamentally different. Faculty noted that textbooks had particular strengths, like providing a breadth of material that is organized and streamlined in a way that promotes consistency across instructors, ensuring that departmental learning objectives are achieved with a variety of instructors. They explained that the books facilitate content delivery to students with a range of abilities, and that textbooks reduce course preparation time for faculty. Still, the faculty in our study had a strong preference for teaching without textbooks.

Instructors saw alternatives to textbooks, like monographs and articles, as time-intensive to teach, but the best way to advance students' critical reading and thinking skills, a finding congruent with the academic literacy literature. In addition, instructors viewed the task of finding textbook alternatives as a way to engage their own critical reading and thinking skills in their teaching, a benefit rarely discussed in the literature. We argue that teaching courses with alternative readings creates a course experience where both students and faculty engage in evaluative reading and creative reasoning. Unfortunately, according to our participants, the conversations regarding course design around textbook alternatives are lacking on campus. The overwhelming majority of faculty in the study received no training or mentoring from their department or institution. Therefore, the paper concludes with advice from study participants for faculty interested in teaching with alternatives to textbooks. 


\section{Literature Review}

\section{Textbooks and Learning}

One type of text that undergraduate students have extensive experience reading is the textbook. A nation-wide study of 2,711 faculty representing a full-range of educational institutions and disciplines found that $68 \%$ of US faculty required textbooks (Seaman \& Seaman, 2017, p. 7). While textbooks have some benefits, including delivering extensive content in an image-rich format that students are familiar with, teaching and learning scholars tend to criticize this type of reading.

In sociology, complaining about undergraduate textbooks is a "venerable" (Schweingruber, 2005, p. 81) and "time honored" (Zipp, 2012, p. 307) tradition. For decades sociologists have critiqued textbooks as formulaic in structure and uniform in content, but while they lamented these shortcomings they explained that they are a product of professors wanting to reduce their course preparation time, students wanting easy readings, and publishers wanting a profit (Graham, 1988; Macionis, 1988; Ritzer, 1988). More recently scholars in sociology have analyzed textbooks to debate the foundation of knowledge in the discipline, often referred to as the "core" (Keith \& Ender, 2004; Schweingruber, 2005). A current cleavage about teaching the core concerns whether instructors should prioritize content breadth or skill development (Ballantine et al., 2016; Greenwood \& Howard, 2011). Many argue for both, but contend that textbooks tend to skim too much material because the primary goal of these books is to deliver as much content as possible (Ballantine et al., 2016; Greenwood \& Howard, 2011; Zipp, 2012).

In other disciplines scholars argue that textbooks create a reading experience that bores students and reduces student engagement (Carnevele, 2006; Dardig, 2008; Shibley, Dunbar, Mysliwiec, \& Dunbar, 2008). Part of the problem is that textbooks can reduce complexity in order to cover content in a way that is streamlined and accessible, giving little room for students to disagree or come up with original ideas (Pawan \& Honeyford, 2009; Pugh, Pawan, \& Antommarchi, 2000; Westhues, 1991). As Pawan and Honeyford (2009) explain, textbooks provide "an absolutist and passive approach to learning" because they do not invite students to read critically or personally define conclusions regarding content, instead they push students to accept the authority of external sources of knowledge (p. 27).

In sum, scholars in sociology and other disciplines identify problems with textbooks arguing that the books tend to be formulaic and over-simplified, which reduces student engagement and learning. The academic literacy scholarship reviewed below explains how alternative texts like journal articles and monographs, combined with active reading instruction, helps faculty teach students how to critically think and read in discipline specific ways.

\section{Critical Thinking and Critical Reading}

Academic literacy scholarship focuses on the particular ways of knowing and communicating within a discipline (Gee, 2010). This scholarship contends that areas of study have distinctive social and cultural practices that are reflected in textual styles and conventions, thus faculty need to teach students how to read assigned texts in particular courses and in particular majors (Gee, 2010; Van Camp \& Van Camp, 2013). Importantly, the type of texts faculty assign, specifically textbooks or reading alternatives like journal articles and monographs, pose different opportunities for critical reading and more broadly, critical thinking.

It is commonly understood that critical thinking involves more than information recall about a body of knowledge. Rickles, Schneider, Slusser, Williams, and Zipp (2013) conceptualize critical thinking as a process that involves critical reasoning which is used to assess "the logical or empirical 
sufficiency of a statement" and creative reasoning that "defends a logical and empirical statement that has been created" (p. 272). Faculty can improve student critical thinking skills by creating opportunities for students to assess thinking in the discipline (Broadbear, 2003). Broadbear (2003) argues that some types of assigned readings can advance this goal, as collections of complex texts can show expert disagreement, requiring students themselves to interpret and assess evidence, which promotes critical reasoning. Roberts and Roberts (2008) argue that this type of reading can also develop creative reasoning, where students read to construct their own arguments. Pugh, Pawan, and Antommarchi (2000) add that well-selected readings can be a platform from which instructors and students launch critical thinking in collaboration with each other (p. 25).

Simply assigning complex readings is insufficient. Professors need to actively teach undergraduates to read in order for them to develop academic literacy. Van Camp and Van Camp (2013) contend that professors mistakenly assume that students have college-level reading abilities. They conceptualize college-level reading as "critical reading," where a reader "can identify what a text does, and how" in order to evaluate the text and ultimately engage with it in their own thinking (Van Camp \& Van Camp, 2013, p. 88). Evaluating a text and using a text to develop original thought are the critical reasoning and creative reasoning skills that together, comprise the Rickles et al. critical thinking conceptualization (2013). The concept critical reading does not duplicate the broader concept critical thinking. Critical reading brings attention to skills that are required to effectively critique and analyze texts. Critical reading then, functions as a building block for creating broader critical thinking outcomes, such as the ability to synthesize a literature, conduct original research, and write a research paper.

Professors can teach the skills needed to read and decipher difficult texts by providing scaffolding, learning tools, and regular assessments (Pugh et al., 2000). Multiple authors advise structured reading techniques that encourage students to slow down to ask and answer particular questions of the text they are engaged with (Keller, 2008; Macpherson Parrott \& Cherry, 2011; Rautman, 2014; Roberts \& Roberts, 2008; Williams, 2005). For example, regularly assigned small writing assignments that ask students to identify the thesis statement and supporting evidence in assigned texts promotes reading comprehension, critical reading, and student writing because students learn to model this style (Van Camp \& Van Camp, 2013). Faculty can successfully develop student critical reading and critical thinking, but to do so they need to consciously work towards this goal in their course design, both through the selection of texts as well as teaching students how to critically read these texts.

Academic literacy scholarship contends that eschewing textbooks, and instead choosing more difficult texts that reflect norms in the discipline can develop student critical reading skills, which can lead to broader critical thinking learning outcomes. It is unclear whether this message has reached faculty. Most scholars in this area provide case studies focused on student data from their own courses that explain how particular assignments develop students' reading skills, critical thinking, and learning (Keller, 2008; Roberts \& Roberts, 2008; Van Camp \& Van Camp, 2013; Williams, 2005). The few studies that sample from a larger population of professors tend to be quantitative surveys about textbook adoption that are concerned with availability, new digital products, and cost, rather than learning outcomes like critical reading and thinking (Seaman \& Seaman, 2017; Zogby International, 2004).

This study contributes to the literature by examining the text selection choices sociology faculty at multiple institutions make, and their perceptions of how their text choices influence their teaching and student learning. We find that faculty explanations of their teaching practices correspond to the literature. Faculty in our sample widely disparage textbooks and use alternative readings primarily to develop student critical reading and thinking skills. While the critical reading and thinking literature focuses on students, our focus on teachers reveals that faculty also value using alternatives 
to textbooks because reviewing and selecting scholarly texts in the discipline engages their own critical reading and thinking as they design and teach courses.

\section{Methods}

To research text selection practices and how faculty understand these choices we designed a survey that included both closed-ended questions which we compiled with descriptive statistics and openended questions that we analyzed using qualitative coding. The qualitative results are the analytical core of this study. According to scholarship on qualitative methodology, open-ended survey questions generate responses which can provide "a window into human experience" (Ryan \& Bernard, 2000, p. 769). Our research design relies on multiple personal narratives, or first-person experienced-based accounts where faculty analyze the data afforded by day-to-day teaching and describe solutions to the problems they encounter (Weimer, 2016).

Because the majority US faculty use textbooks (Seaman \& Seaman, 2017, p. 7), we designed the study to increase the likelihood that our sample included faculty that use alternatives to textbooks in their teaching. The study used non-random purposive sampling to identify a pool of sociology faculty who were likely to have text selection autonomy, to teach small to medium-sized classes (at or below 50 students), and be employed by institutions that prioritize teaching. Our focus on sociology instructors stems from our own location in this discipline and our desire to advance our own pedagogy through research. We began with a population of colleges and universities in one western state, then excluded large research universities since faculty are more likely to be research focused, public universities because they tend to have large class sizes, and community colleges because faculty are often required to choose from a pool of pre-selected textbooks. Sixteen private colleges and universities with sociology departments fit our criteria. We identified one hundred and sixty-five sociology professors of all ranks at these institutions. After three e-mailed invitations to join the study we achieved a $22.9 \%$ response rate, with a final sample of thirty-six instructors at twelve institutions. Twenty-two respondents taught at least one class with a textbook and fourteen taught all of their courses without them.

The institutions had average class-sizes ranging from ten to twenty-nine students, and their selectivity measured by acceptance rates ranged from $14 \%$ to $71 \%$. The faculty in the sample all taught undergraduates and, as shown in Table 1, include lecturers, assistant, associate, and full professors, the majority of which were White and female.

\section{Table 1. Survey Respondent Characteristics (N 36)}

\begin{tabular}{lll}
\hline Sex & $\boldsymbol{N}$ & Percentage \\
Female & 24 & $67 \%$ \\
Male & 11 & $31 \%$ \\
No answer & 1 & $3 \%$ \\
Race/Ethnicity & & \\
African-American & 1 & $3 \%$ \\
Latino & 1 & $3 \%$ \\
White & 26 & $72 \%$ \\
Asian & 3 & $8 \%$ \\
Other & 3 & $8 \%$ \\
No answer & 2 & $6 \%$
\end{tabular}

Journal of the Scholarship of Teaching and Learning, Vol. 19, No. 2, March 2019. josotl.indiana.edu 


\section{Teaching Status}

$\begin{array}{lll}\text { Lecturer } & 6 & 17 \% \\ \text { Assistant professor } & 14 & 39 \% \\ \text { Associate professor } & 7 & 19 \% \\ \text { Full professor } & 9 & 25 \%\end{array}$

Twenty-four professors in our sample attended liberal arts institutions when they were undergraduates, while twelve attended research universities. The faculty in the sample teach many different courses. The mean for distinct courses taught in the last five years was 6.1, and the range was from two to fifteen.

We pre-tested the survey questions with a small pilot using a convenience sample, resulting in some useful revisions. The final survey instrument included questions about text selection, benefits and costs for faculty and students, and instructor training. To reduce interviewer bias and improve reliability we took steps to ensure that we presented the research in a neutral way and avoided leading questions. In this vein we asked similar questions about teaching with textbooks and teaching with alternatives. For example, we asked about the benefits of textbooks as well as the benefits of using other types of texts. The survey was web-based, self-administered, and anonymous which increases the likelihood of honest responses (Neuman, 2006, p. 284). The open-ended questions allowed respondents to explain why they choose particular types of texts and how these choices shape course design, classroom teaching, and student learning. To analyze the responses we open-coded to inductively identify themes, which we compiled into a code book, then returned to the data to re-code using the code list (Ryan \& Bernard, 2000).

The research has limitations. The sample is purposive. The results should not be generalized to the overall US faculty. The research does not assess student understandings of the connection between text choice and learning, or test student learning outcomes using quasi-experimental procedures. Instead, the research focuses on faculty. We explain, from a faculty point of view, why instructors choose certain types of texts and the outcomes of these choices.

\section{Results}

The results section starts with the descriptive statistics we generated from the study's closed-ended questions about faculty text selection patterns and attitudes. Then, we present our qualitative analysis of the open-ended questions to explain why our respondents choose textbooks or their alternatives, identifying critical reading and critical thinking in both students and teachers as a key concern. Table 3 presents the critical reading and thinking analytic framework of the comparison of textbook oriented courses and courses using textbook alternatives. We finish with a section on implications for practice which covers course design, teaching reading, preparing lectures, and the expense of required readings.

\section{Faculty Text Selection Patterns and Attitudes}

Faculty use a variety of reading material in their courses and most combine different types of texts. Figure 1 shows that faculty in the study were most likely to assign journal articles and readers in their lower division courses and most likely to assign journal articles and monographs in their upper division courses. 


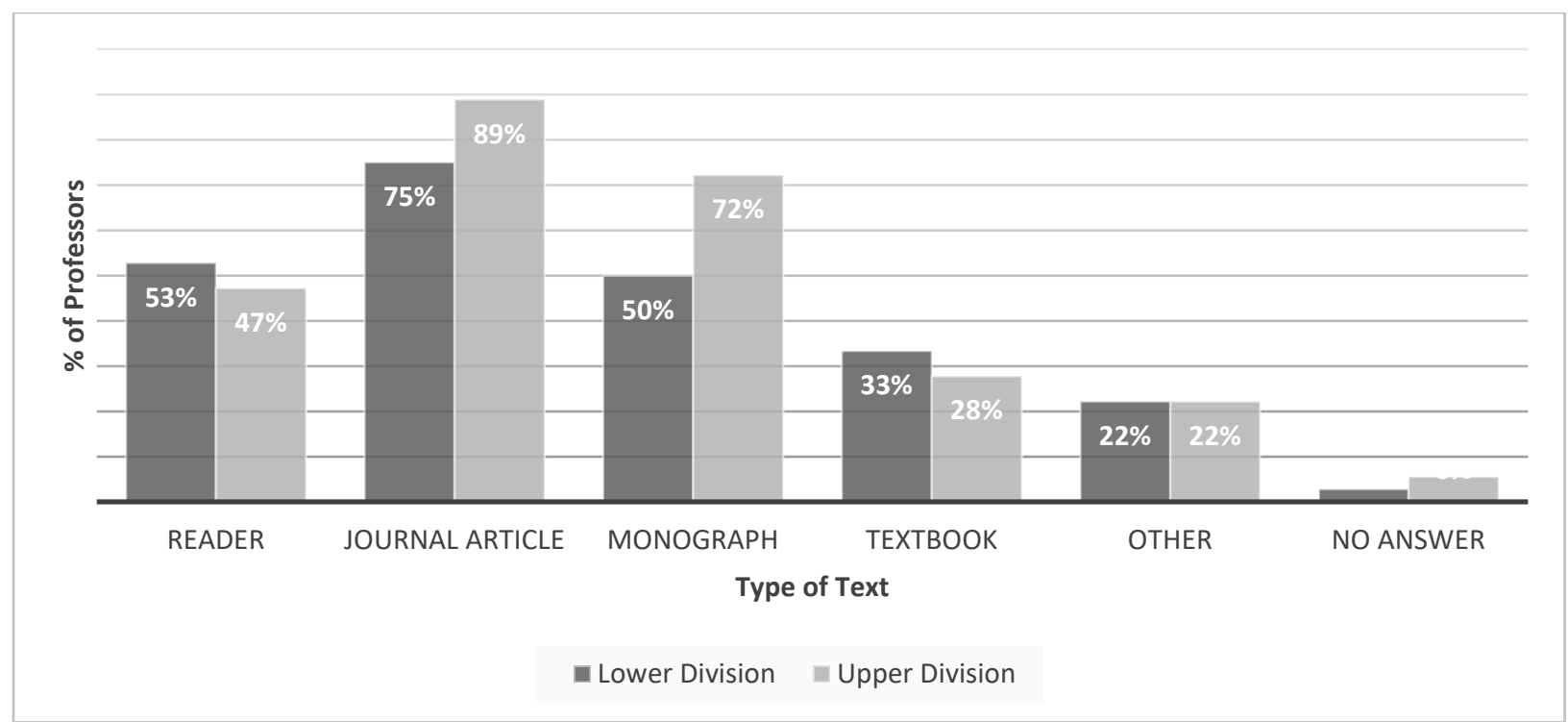

Figure 1. Text Selection in Upper and Lower Division Courses

Faculty were least likely to assign textbooks in all of their courses, not counting "other." Other reading sources used include newspaper and news-magazine articles, blogs, and specific book chapters. Faculty were more likely to assign readers and textbooks in lower division classes than upper division, demonstrating that faculty increase text complexity as students advance through the discipline. However, faculty commonly challenged lower division students with scholarly readings in their original published form, as shown by the inclusion of journal articles in 75\% of lower division courses.

Faculty attitudes about student learning in courses with particular types of texts are shown in Table 2. We asked instructors to identify the type of course that best advances student learning. Many respondents thought courses with and without textbooks were equally beneficial, but more faculty identified courses without textbooks as better at advancing student learning, especially in upper division classes.

Table 2. Faculty attitudes about types of courses that best advance student learning

\begin{tabular}{lll}
\hline Lower Division & $\boldsymbol{N}$ & $\%$ \\
A Course With a Textbook & 6 & $17 \%$ \\
A Course Without a Textbook & 16 & $44 \%$ \\
Equal & 14 & $39 \%$ \\
\hline Upper Division & & \\
A Course With a Textbook & 0 & $0 \%$ \\
A Course Without a Textbook & 26 & $72 \%$ \\
Equal & 10 & $28 \%$ \\
\hline
\end{tabular}

No respondents believed that courses that use textbooks were the best choice for student learning in upper division classes, but $17 \%$ of instructors said textbooks were superior in lower division courses. In contrast, faculty were more likely to view courses without textbooks to be the best way to advance student learning, especially in upper division courses, with $72 \%$ of respondents taking this position. A fair number of respondents felt that courses with and without textbooks were both effective at advancing student learning, with $28 \%$ of respondents choosing "equal" for upper division courses and $39 \%$ choosing this response for lower division courses. 


\section{Explaining Text Selection Patterns and Attitudes: the Importance of Critical Thinking and Critical Reading}

Our primary research goal was to understand how faculty see the relationship between text selection, teaching, and learning, therefore we asked faculty to explain the costs and benefits of particular texts. When asked close-ended questions, as shown in Table 2, many faculty said courses with textbooks and courses without textbooks were equal at advancing student learning. In contrast, faculty responses to open-ended questions demonstrated strong attitudes in support of teaching without textbooks, primarily because they argued that alternative readings develop critical reading and thinking skills. Our inductive qualitative analysis of open-ended survey interview questions, revealed that faculty construct textbooks and their alternatives as having key differences. In Table 3 we present the analytical framework.

\begin{tabular}{|c|c|c|}
\hline Dimensions & Textbooks & Textbook Alternatives \\
\hline \multicolumn{3}{|l|}{ Text Qualities } \\
\hline Coverage of Material & Breadth & Depth \\
\hline Difficulty & Straightforward & Rigorous \\
\hline Objectives & Deliver content & Contribute to the discipline \\
\hline \multicolumn{3}{|l|}{ Teaching/Learning } \\
\hline Faculty/Student Roles & Expert/Novice & Co-learners \\
\hline Synthesis & Done by textbook & Done by faculty and students \\
\hline Evaluation and Critique & Done by textbook & Done by faculty and Students \\
\hline Role of faculty in course design & Replication & Creation \\
\hline
\end{tabular}

Assigning textbook alternatives, according to faculty, is useful for developing student critical reading skills which leads to critical thinking outcomes. Monographs and journal articles help promote critical reading because these texts represent the scholarly writing of the discipline in its original published form, therefore these rigorous, in-depth texts promote disciplinary literacy. Readers can start to identify what authors work to achieve in their texts and how they follow conventions, which students can ultimately model in their own thinking and writing (Van Camp \& Van Camp, 2013, p. 88). Returning to the critical thinking concept introduced in the literature review, the evaluation and critique work is critical reasoning because students assess the logical and empirical quality of an individual text (Rickles et al., 2013, p. 272). The synthesis work that students do across multiple assigned readings is creative reasoning, as they create logical and empirical connections across texts (Rickles et al., 2013, p. 272). In addition, using textbook alternatives has critical thinking outcomes for faculty as well. While choosing multiple readings instructors evaluate and synthesize the literature in order to create a course. Faculty, though certainly not novices, engage their skills as they work through texts with students.

Teaching with Textbook. Alternatives. When asked to explain how using alternatives to textbooks benefits students, the most common response was that original texts like monographs and articles provide depth and complexity that advance critical thinking. Instructors described monographs and articles as "real" and "actual research" which the academic literacy literature explains provides critical reading opportunities for students. As one faculty member wrote, for most "courses I prefer to create a context that requires students to do the critical work of analysis and organization themselves." This was seen as especially important in upper division courses as a faculty explained, "I expect upperdivision courses to have nuance and complexity and I expect students to take responsibility for more 
of the analytic work - to do that they need to practice engaging complex texts [and] arguments and they need to learn to connect [and] compare arguments [and] data."

In response to various questions faculty alluded to what critical reading and critical thinking meant to them. They described these processes as a way to "evaluate strengths and weaknesses," to "synthesize the readings and find meaning through their own efforts rather than through reading the conclusions drawn by someone else," and to have "critical discussions of research methods and analytic claims." They wrote that using monographs and articles in a course helps instructors encourage students to "grapple with ideas" and learn how to disagree with an author's arguments or critique their methods. In contrast, one professor stated, textbooks "appear to be objective and full of 'right' answers and 'right' perspectives" denying students the ability to be part of the intellectual conversation.

Many faculty disparaged textbooks as "boring," "overly generalized," "simplistic," and "dumbed-down" none of which promotes critical reading. One respondent explained that some textbooks "spoon-feed the material to students," other respondents described textbooks, with their "pre-digested" material and "summaries" as promoting "content consumption" and "memorizing." Not surprisingly, many identified these texts as detrimental to students. As one respondent said, textbooks "get in the way of intellectual engagement." The faculty in this study tended to value developing an analytical skillset over teaching a breadth of content, joining a group of sociological pedagogy scholars that also argue for praxis (Ballantine et al., 2016; Greenwood \& Howard, 2011; Zipp, 2012).

Faculty also valued how textbook alternatives stimulated their own engagement. When faculty design courses using journal articles and monographs, they critically read texts, then curate content, all the while considering student capacity and interests. Through their selection of texts faculty are making an argument about the discipline, as these texts function as exemplars that illustrate classic works, key theories, current debates, research methodologies, and disciplinary writing. Collections of texts in a course demand synthesis, faculty create connections and identify conflicts across the reading materials but also create opportunities for undergraduate students to do the same, thus engaging and promoting critical and creative reasoning in a classroom community.

Faculty described their own critical reading and critical thinking work in designing courses with textbook alternatives as one of the benefits of not using textbooks. As one respondent wrote, when faculty use alternatives to textbooks, teaching "comes from the mind and the heart of the instructor." Another added, textbooks "are based on the editor's views - with this [textbookalternative] technique, I am the editor of my own class materials." They explained that without textbooks it is important to "think deeply about what you are doing" and "engage intellectually with your discipline." Many agreed that this means in total that you have to spend "more time on your teaching." As one respondent said, teaching without a textbook requires "lots of work on the instructor's part" and respondents explained that this extra work takes place across most areas of teaching including syllabus construction, assessment design, and day-to-day in-class activities. In sum, there are critical thinking and critical reading benefits for students and faculty, as one responded explained, "Students and professors have to think harder and work together more to make sense of the material."

Teaching with Textbooks. When we asked respondents to identify the benefits of textbooks for students, they noted that textbooks can provide breadth, organization, and ease of use. Some respondents explained that textbooks are efficient vehicles for delivering extensive content. Content, of course, is a key component of many college courses and can be a necessary knowledge base for future classes. Others noted that textbooks can provide cohesive overall course structure, as one respondent explained, textbooks "provide a clear structure" and have a "logical flow." Professors noted that this organization can make learning more straightforward for students as a good textbook,

Journal of the Scholarship of Teaching and Learning, Vol. 19, No. 2, March 2019.

josotl.indiana.edu 
"outlines what they should learn [and] provides clear explanations." They further explained that this gives students a "sense of security" and allows "weaker students [to] have something to hold onto and aid them if they get behind." A few respondents identified supplemental materials as a benefit for students, mentioning glossaries, indexes, study guides, vocabulary lists, reflection questions, and online components.

A small number of respondents said that the homogeneity of textbooks helped students advance through the curriculum because they ensured similar types of exposure to the discipline in lower-division courses regardless of the professor. As one respondent explained, "textbooks make it likely certain core material will be taught in all sections [of the same course]," and conversely when "readings are used, sections of the same course are less similar because they don't cover the same material." Respondents also identified textbooks as a protection against bad teaching. As one respondent wrote, a textbook "minimizes the effects of poor teachers because even if the teacher isn't great, all students have access to the same information." Another wrote, "Use of a textbook guarantees the student will gain some basic knowledge of the field from the course."

When we directly asked respondents about the strengths of textbooks, they identified the benefits outlined above, however, respondents were more likely to criticize textbooks than other types of readings. As one respondent vehemently wrote, "use texts and you are miss-educating your students" and another disparaged, "I suppose if you have very large classes and no interest in teaching they [textbooks] are the only way to go." Others negated their positive comments with qualifying statements like, students "get a (I think false) sense of coherence if the book is well edited" or that textbooks can be good if they are not overly "textbooky."

When we asked respondents to explain the benefits of textbooks for instructors, faculty explained that textbooks make teaching "easy" and were "a time saver." Instructors saw textbooks as a way to save prep-time, including not having to choose a selection of readings, to write exams, or to organize a syllabus from scratch. As one explained, the "material is already organized and structured." Another said that using a textbook means "less work finding reading material and coming up with accompanying assignments." One participant explained, "someone else has done the main part of the work, so we don't need to reinvent the wheel." A few others noted that textbooks help in "sub-areas with which we are less familiar" and similarly, instructors can "teach a variety of subjects without worrying as much about their own expertise." In sum, a major benefit of textbooks for instructors was they reduce preparation time.

Faculty designing courses with textbooks replicate more of their course design and content, which saves time, while faculty who use alternatives to textbooks engage in more creation, which is time consuming. We argue that course creation work without a textbook requires more synthesis, evaluation, and critique, meaning that faculty are critically reading and thinking in order to design their courses. Thus, faculty and students have a co-learning role, where their critical reading and thinking skills are developed and practiced as they teach and learn together. This model does come with potential costs beyond the extensive faculty time investment. It reduces the ability to transmit the core foundational knowledge in the discipline and increases the potential for idiosyncratic teaching and learning.

\section{Implications for Practice}

According to the instructors we surveyed, designing courses using alternatives to textbooks can be difficult for faculty and learning without a textbook can be challenging for students. Unfortunately, according to our respondents there are few face-to-face conversations on campus about designing courses around textbook alternatives. In our study, the overwhelming majority of respondents received no training or mentoring from their department $(89 \%)$ or their institution $(94 \%)$ in text

Journal of the Scholarship of Teaching and Learning, Vol. 19, No. 2, March 2019.

josotl.indiana.edu 
selection and related teaching practices. When we asked how they learned to teach without a textbook, most said they modeled their classes from their own experiences as a learner. Others modeled their courses on their graduate education, as one wrote, "I thought about my graduate education and those seminars were frequently based on current readings and supplemented by classic works." A few noted that they learned from being a Teaching Assistant for professors with good teaching strategies. Only a few respondents mentioned that they talked to colleagues, borrowed syllabi, or read pedagogy literature. Certainly though, sociology instructors do share teaching ideas and resources through TRAILS, an online peer-reviewed library of sociology teaching resources, the Facebook group "Teaching with a Sociological Lens," which has over 4,000 members, and Twitter, where teaching focused accounts like@TheSocyCinema have over 14,000 followers. Still, this research suggests limited discussion about text selection making our question "what advice would you give to an instructor that is considering teaching without a textbook" useful. Here, we synthesize comments from our respondents to provide guidance for faculty that use textbook alternatives or are experimenting with them for the first time.

Course Design. When teaching without a textbook it is the job of the faculty to create the structure and sense of the discipline or sub-discipline that textbooks provide. Many of the respondents made clear the preparatory work involved with teaching with textbook alternatives. Without a textbook and accompanying supplemental materials, it is now the professor's job, as one respondent explained, to "ensure readings and course materials are tightly coupled with course objectives." During the course development phase one respondent noted that, "It is helpful to think through the main topics [and] issues you want to cover in the course before choosing specific readings." The respondent counseled that, "sometimes browsing a textbook is helpful to see how traditional textbooks carve up the topics." Once a professor has an overall structure of the course in mind, a respondent advised, "Pick three to four timely topical books" and "assure that they increase in their theoretical complexity as you go through the semester." Respondents recommended that monographs be "engaging" and "readable" but also that faculty need to be aware that, as one faculty explained, "there are things you might love that will never work in a class."

Teaching Reading. Our respondents, valued alternatives to textbooks, like research articles and academic monographs because these texts are more likely to have challenging content and reflect the practices of the discipline which promotes critical reading. As one faculty member explained, students "will learn far better by engaging with concrete examples of good... research, taken from a few areas of the discipline." However, academic monographs and research articles are primarily written for readers with more background and formal training in the discipline, creating challenges for undergraduate students. To address this, respondents recommended assigning regular graded and ungraded activities that provide structure and scaffolding to help students learn to critically read academic texts. Because of the challenges of difficult readings it is important as one instructor in our sample asserted, to "design assignments that assure reading and comprehension" and another advised to "assess students early and often." Describing assignments in detail is outside the scope of this paper, however the works cited includes numerous published examples of assignments that promote critical reading (Keller, 2008; Macpherson Parrott \& Cherry, 2011; Roberts \& Roberts, 2008; Van Camp \& Van Camp, 2013; Williams, 2005).

Lecture. Professors identified organization as one of the key teaching and learning challenges in courses that do not use textbooks. One instructor noted that students "may have a harder time synthesizing the concepts they are reading in individual texts." We note that synthesis requires creative reasoning. A few others wrote that students can "get lost" without a textbook and that a textbookfree course "might feel disorganized." Many respondents shared that good lectures can address some of these problems. Lectures can help students situate particular readings into broader disciplinary ideas and practices. One professor counseled, "I think the professor really has to work long and hard at

Journal of the Scholarship of Teaching and Learning, Vol. 19, No. 2, March 2019.

josotl.indiana.edu 
making the books seamlessly work with each other." Without the structure of the textbook, it falls on faculty and students to create connections between individual readings and the discipline as a whole. In addition, to address the problem of students having partial learning, one instructor suggested that teachers "develop a solid set of lectures to provide all background so students get more out of the substantive readings you assigned." For lower division courses in particular a respondent said, "You have to be able to deliver the essential concepts... in other ways and then build those tools into the discussion of monographs, readers, media sources and other [materials]."

Cost. While pedagogy was the primary concern of the faculty we surveyed, they were also attuned to the financial burdens their students face. Texts can add to the cost of college. In the words of one respondent, textbooks are "exceedingly expensive." One textbook user explained, "I honestly feel bad sometimes having students pay the exorbitant prices." Some said that new editions makes it difficult to buy a used copy and to keep a copy on library loan, which increases cost. One respondent noted that the cost might keep students from buying the book resulting in lower reading compliance. Some remarked that the problem is most acute for low-income students. A nation-wide survey of faculty shows similar concerns about the high price of textbooks and fears that these prices reduce student purchasing of required books (Seaman \& Seaman, 2017).

Our participants' worry about the cost of textbooks is part of current discussions about the increasing cost of college. The United States Congress requested a government investigation of the textbook industry to understand the role of textbooks in the increasing cost of higher education (United States Government Accountability Office, 2005). The research found that between 1986 and 2004 textbook prices nearly tripled, an increase twice the rate of inflation (United States Government Accountability Office, 2005, p. 2). Prices continue to grow. From January 2006 to July 2016 consumer prices for college textbook increased 88 percent (Bureau of Labor Statistics, 2016). Concerns over price have spurred a flurry of articles advocating for ditching textbooks and replacing them with free digital materials. Faculty from across academia argue that much free and up-to-date information from multiple perspectives is available on-line, through government websites and other reputable sources making textbooks relics of a pre-digital age (Carnevele, 2006; Talbert, 2007). Other faculty are retaining textbooks, but are choosing free or very little cost options that are open educational resources provided by non-profit organizations like OpenStax or state initiatives like the California Digital Open Source Library (Ozdemir \& Hendricks, 2017; Seaman \& Seaman, 2017). While none of our respondents advocated for abandoning hard-copy books altogether, they did suggest that alternative readings can reduce costs by providing free digital materials on course management systems, as well as lower-cost printed material.

\section{Conclusion}

Text selection is an important course design decision. This research sheds light on the types of texts faculty assign, focusing on textbooks and their alternatives, as well as how faculty understand the consequences of these choices on teaching and learning. The research adds to a literature that primarily consists of case studies and focuses on learners more than teachers. The sociology faculty we surveyed were more likely to assign journal articles, monographs, and readers than textbooks in both upper division and lower division courses. However, over half of the sample used textbooks in at least one of their classes. Inductive analysis of qualitative comments revealed that faculty view textbooks and alternative readings as fundamentally different. Faculty believed that courses using alternatives to textbooks best advance student learning, specifically critical reading and critical thinking, where students evaluate and critique texts in order to create their own analyses. However, they noted that textbooks excel at delivering large amounts of homogeneous content in an organized manner, which ensures that certain topics are explored regardless of the quality, training, or interests of particular

Journal of the Scholarship of Teaching and Learning, Vol. 19, No. 2, March 2019.

josotl.indiana.edu 
instructors. While faculty stated that textbooks can reduce the time it takes to design a course, they valued how choosing alternative readings engaged their own critical and creative reasoning as they selected texts and worked through the readings alongside students.

Most faculty in United States colleges and universities use textbooks. This study is not a critique of their practice. Our survey respondents, sociology faculty at small private institutions in one Western state, were chosen because we determined they would have a higher likelihood of teaching with a variety of texts due to their institutional context. Faculty at larger institutions and in other disciplines are faced with a different set of opportunities and constraints, as well as disciplinary cultures, which shape text selection and teaching. As Gee (2010) explains, literacy develops within particular contexts. Nonetheless, this research suggests that faculty should consider using textbook alternatives, which combined with purposeful teaching, can promote critical reading and critical thinking learning outcomes, as well as bring faculty and students together into a learning community. While some might believe that only the most prepared students are ready for disciplinary texts in their original form, faculty in this study taught in institutions with widely varying acceptance rates, suggesting different student preparation levels, yet they assigned difficult readings. In addition, faculty also commonly used journal articles and monographs in lower division courses populated by students new to the discipline. Careful curation of readings, combined with academic literacy instruction, is crucial for success.

Instructors suggest that teaching with textbook alternatives requires practices that differ from teaching with textbooks. This approach requires more investment in course design, including choosing topics and readings, and creating assignments and lectures that provide synthesis, organization, and background. They also suggest that investing more time in teaching literacy skills and assessing these skills is essential. As one professor counseled, aim high and "assume your students are capable of understanding research and theoretical monographs [and] articles with your guidance." The benefit for students and faculty is more authentic engagement with the discipline in their courses, giving them both opportunities to evaluate and critique texts and create their own analyses.

\section{References}

Ballantine, J., Greenwood, N., Howard, J. R., Kain, E. L., Pike, D., Schwartz, M., . . Zipp, J. F. (2016). Does the center hold? Reflections on a sociological core. Teaching Sociology, 44(3), $151-$ 162. doi:10.1177/0092055X16647432

Broadbear, J. T. (2003). Essential elements of lessons designed to promote critical thinking. The Journal of Scholarship of Teaching and Learning, 3(3), 1-8.

Bureau of Labor Statistics. (2016). The economics daily, College tuition and fees increase 63 percent since January 2006. Retrieved from https://www.bls.gov/opub/ted/2016/college-tuitionand-fees-increase-63-percent-since-january-2006.htm

Carnevele, D. (2006). An environmental-science course ditches textbook. http://chronicle.com/article/An-Environmental-Science/18490/

Dardig, J. C. (2008). Throw away your textbook and increase discussion. College Teaching, 56 (2), 128128. 
Gee, J. P. (2010). A situated sociocultural approach to literacy and technology. In E. A. Baker (Ed.), The New Literacies: Multiple Perspectives on Research and Practice (pp. 165-193). New York: Guilford.

Graham, F. (1988). Some observations on sociology textbooks: An editorial perspective. Teaching Sociology, 16(4), 356-365.

Greenwood, N. A., \& Howard, J. R. (2011). First contact: Teaching and learning in introductory sociology. Rowman \& Littlefield Publishers.

Keith, B., \& Ender, M. G. (2004). The sociological core: Conceptual patterns and idiosyncracies in the structure and content of introductory sociology textbooks, 1940-2000. Teaching Sociology, 32(1), 19-36.

Keller, J. G. (2008). Questions first: Introducing critical thinking using the Text Analysis Matrix (TAM). Journal of the Scholarship of Teaching and Learning, 8(2), 11-24.

Macionis, J. (1988). Textbooks and sociology: A case of professional dependency. Teaching Sociology, 16(4), 420-423.

Macpherson Parrott, H., \& Cherry, E. (2011). Using structured reading groups to facilitate deep learning. Teaching Sociology, 39(4), 354-370.

Neuman, L. W. (2006). Social research methods: Qualitative and auantitative approaches. Boston, MA: Pearson Education, Inc.

Ozdemir, O., \& Hendricks, C. (2017). Instructor and student experiences with open textbooks, from the California open online library for education (Cool4Ed). Journal of Computing in Higher Education, 29(1), 98-113. doi:10.1007/s12528-017-9138-0

Pawan, F., \& Honeyford, M. A. (2009). Academic literacy and the new college learner. In R. F. Flippo \& D. C. Caverly (Eds.), Handbook of College Reading and Study Strategy Research (pp. 2646). New York: Routledge.

Pugh, S. L., Pawan, F., \& Antommarchi, C. (2000). Academic literacy and the new college learner. In R. F. Flippo \& D. C. Caverly (Eds.), Handbook of College Reading and Study Strategy Research (pp. 25-42). London: Lawrence Erlbaum Associates, Publishers.

Rautman, A. E. (2014). A student's guide to critical reading using APPS. College Teaching, 62(2), 76-76.

Rickles, M. L., Schneider, R. Z., Slusser, S. R., Williams, D. M., \& Zipp, J. F. (2013). Assessing change in student critical thinking for introduction to sociology classes. Teaching Sociology, 41(3), 271-281. doi:10.1177/0092055x13479128

Ritzer, G. (1988). Problems, scandals, and the possibility of 'Textbookgate': An author's view. Teaching Sociology, 16(4), 373-380. 
Roberts, J. C., \& Roberts, K. A. (2008). Deep reading, cost/benefit, and the construction of meaning: Enhancing reading comprehension and deep learning in sociology courses. Teaching Sociology, 36(2), 125-140.

Ryan, G. W., \& Bernard, H. R. (2000). Data management and analysis methods. In N. K. Denzin \& Y. S. Lincoln (Eds.), The SAGE Handbook of Qualitative Research. Thousand Oaks: Sage.

Schweingruber, D. (2005). Looking for the core in the wrong place. Teaching Sociology, 33(1), 81-89.

Seaman, J. E., \& Seaman, J. (2017). Opening the textbook: Educational Resources in U.S. Higher Education, 2017. Retrieved from https://www.onlinelearningsurvey.com/reports/openingthetextbook2017.pdf

Shibley, I., Dunbar, M. E., Mysliwiec, T. H., \& Dunbar, D. A. (2008). Using science popularizations to promote learner-centered teaching: Alternatives to the traditional textbook. Journal of College Science Teaching, 38(2), 54-58.

Talbert, R. (2007). Reconsidering textbooks. Retrieved from http://chronicle.com/blognetwork/castingoutnines/2007/03/06/reconsidering-textbooks/

United States Government Accountability Office. (2005). College textbooks: Enhanced offerings appear to drive recent price increases. Retrieved from https://www.gao.gov/new.items/d05806.pdf

Van Camp, D., \& Van Camp, W. (2013). Using content reading assignments in a psychology course to teach critical reading skills. Journal of the Scholarship of Teaching and Learning, 13(1), 86-99.

Weimer, M. (2016). Personal narratives: Perfect for summer reading. Retrieved from http://www.facultyfocus.com/articles/teaching-professor-blog/personal-narratives-perfectsummer-reading/?utm_content $=27719971 \& u t m \_$medium $=$social\&utm_source $=$twitter

Westhues, K. (1991). Transcending the textbook world. Teaching Sociology, 19(1), 87-92.

Williams, S. (2005). Guiding students through the jungle of research-based literature. College Teaching, 53(4), 137-139.

Zipp, J. F. (2012). 2011 Hans O. Mauksch Address: Teaching for whom? Teaching Sociology, 40(4), 301-311. doi:10.1177/0092055X12455650

Zogby International. (2004). The attitudes of college faculty on the textbooks used in their courses. Retrieved from https://www.immagic.com/eLibrary/ARCHIVES/GENERAL/AAP_US/A041231Z.pdf 